\title{
Predictive factors for length of hospital stay following primary total knee replacement in a total joint replacement centre in Hong Kong
}

\author{
CK Lo *, QJ Lee, YC Wong
}

This article was published on 4 Aug 2017 at www.hkmj.org.

\section{A B S T R A C T}

Introduction: The demand for total knee replacement in Hong Kong places tremendous economic burden on our health care system. Shortening hospital stay reduces the associated cost. The aim of this study was to identify perioperative predictors of length of hospital stay following primary total knee replacement performed at a highvolume centre in Hong Kong.

Methods: We retrospectively reviewed all primary total knee replacements performed at Yan Chai Hospital Total Joint Replacement Centre from October 2011 to October 2015. Perioperative factors that might influence length of stay were recorded.

Results: A total of 1622 patients were identified. The mean length of hospital stay was 6.8 days. Predictors of prolonged hospital stay following primary total knee replacement were advanced age; American Society of Anesthesiologists physical status class 3; bilateral total knee replacement; in-patient complications; and the need for blood transfusion, postoperative intensive care unit admission, and urinary catheterisation.

Conclusions: Evaluating factors that can predict length of hospital stay is the starting point to improve our current practice in joint replacement surgery. Prediction of high-risk patients who will require a longer hospitalisation enables proactive discharge planning.

\section{Hong Kong Med J 2017;23:435-40}

DOI: 10.12809/hkmj166113

CK LO *, MB, BS

QJ Lee, FHKCOS, FHKAM (Orthopaedic Surgery)

YC Wong, FHKCOS, FHKAM (Orthopaedic Surgery)

Joint Replacement Centre, Yan Chai Hospital, Tsuen Wan, Hong Kong

* Corresponding author: Ipluswck@live.com

New knowledge added by this study

- Advanced age; American Society of Anesthesiologists physical status class 3; bilateral operation; in-patient complications; and the need for blood transfusion, postoperative intensive care unit admission, and urinary catheterisation were predictors for length of hospital stay after primary total knee replacement.

Implications for clinical practice or policy

- Prediction of high-risk patients who will require longer hospitalisation based on perioperative factors enables proactive discharge planning.

- Establishment of a urinary catheterisation protocol might help to shorten hospital stay following primary total knee replacement.

\section{Introduction}

With a rising incidence of degenerative arthritis in our ageing population, together with an increase in popularity of joint replacement surgery, the demand for total knee replacement (TKR) is expected to grow in Hong Kong. ${ }^{1}$ This places a tremendous economic burden on our health care system. The associated cost of hospital stay can be reduced by shortening the length of hospital stay (LOS). With more than 3000 TKRs performed in public hospitals in Hong Kong each year, ${ }^{2}$ and given the cost per in-patient day of HK\$4000, shortening the LOS by 1 day could save HK\$12 million every year. Identification of factors that extend hospital stay, which is a starting point for reducing LOS, can reduce the financial burden on the health care system.
The aim of this study was to identify perioperative predictors of LOS following primary TKR in a high-volume centre in Hong Kong.

\section{Methods}

All patients admitted for primary TKR from October 2011 (when the Joint Replacement Centre in Yan Chai Hospital in Hong Kong was established) to October 2015 were included in the study. Data of patients were collected retrospectively from the Clinical Management System of the Hospital Authority. The study was approved by the Kowloon West Cluster Research Ethics Committee.

Patients who undergo TKR in our centre attend a preadmission clinic 1 month before operation for their preoperative work-up and anaesthetic 


\section{香港一所全關節置換中心內進行全膝關節置換術 後病人住院時間長短的預測因素 \\ 羅子健、李君哲、黃耀忠}

引言：全膝關節置換術對香港醫療體系造成巨大的經濟負擔。縮短病 人住院時間可減低相關成本。本研究的目的是找出在香港一所手術病 例量較大的中心進行全膝關節置換術後, 病人住院時間長短的預測因 素。

方法：回顧分析 2011 年10月至2015年10月期間在仁濟醫院全關節置 換中心進行的所有原發性全膝關節置換術的病例。記錄可能影響住院 時間的圍手術期因素。

結果：共1622個病例的平均住院時間為6.8天。接受原發性全膝關節 置換術後可以延長病人住院時間的預測因素有高齡、美國麻醉醫師學 會的身體狀況為三級、雙側全膝關節置換術、住院期間出現併發症, 以及輸血、術後入住重症監護病房和導尿管置入的需要。

結論：要改善關節置換術目前的狀況, 預測病人住院時間的相關因素 可以是第一步。這樣, 醫護人員可以為預測住院時間較長的高風險病 人預先制訂出院計劃。

\section{Admission day}

- Preoperative work-up

- Optimisation of medical conditions

- Referral to physiotherapist, occupational therapist, or medical social worker

- Anaesthetic assessment

- Patient education

- Charting of Knee Score

\section{Day 0}

- Postoperative monitoring

- Supportive care (intravenous fluid, blood transfusion, oxygen, chest physiotherapy)

- Start deep vein thrombosis prophylaxis (mechanical and/or pharmacological on day I)

\section{Day I-3}

- Postoperative check-up, X-ray

- Wound care

- Start ambulation, mobilisation, daily activity training

- Psychosocial condition review, follow-up and discharge plan, and social service arrangement

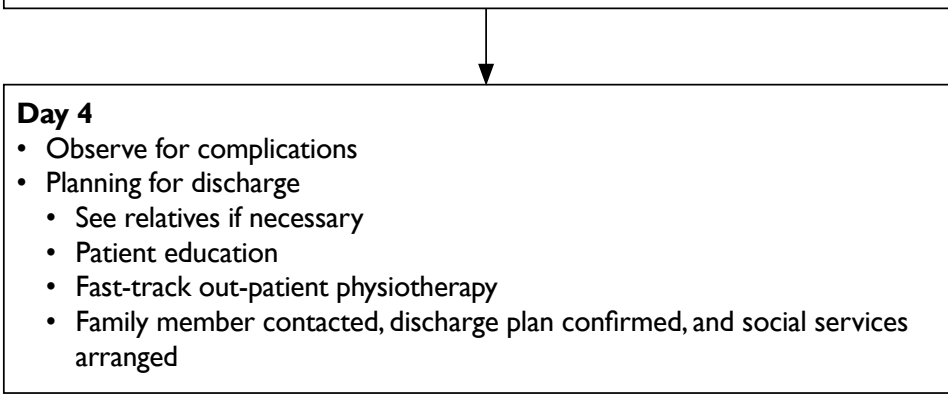

FIG I. Clinical pathway for patients undergoing total knee replacement assessment, and to be given information by surgeons and a specialised nurse about the procedure, rehabilitation, and benefits and complications of TKR. Patients were admitted on the day of surgery or earlier for medical optimisation or social reasons. All operations were performed by or under the supervision of a joint surgeon who adopted a medial parapatellar approach and used a variety of cemented implants. A tourniquet was applied and the patella was routinely resurfaced. A standardised clinical pathway of postoperative monitoring, investigations, mobilisation, and anticoagulation was applied in all patients (Fig 1). Physiotherapy was commenced on the first postoperative day and continued daily until discharge. Patients were cleared for discharge when medically stable, walking independently, and functionally able to return to their home environment. Independent walking was defined as walking stably without assistance from another person with or without a walking aid.

The primary outcome measure of the study was LOS, defined as the number of days in hospital from the day of surgery to the day of discharge. The following factors were analysed: age; gender; body mass index (BMI); American Society of Anesthesiologists (ASA) physical status classification; type of operation (unilateral versus bilateral TKR); preoperative haemoglobin level; in-patient complications; and requirement for postoperative transfusion, drain insertion, postoperative intensive care unit (ICU) care, and urinary catheterisation for postoperative urinary retention. Because the ASA classification has only been documented in the Clinical Management System since August 2014, such information could be retrieved for only 467 patients in this study.

The LOS ranged from 3 to 46 days. Since the distribution was highly skewed, a non-parametric approach was used in the analysis. A univariate analysis for all the studied predictive factors was first performed. Mann-Whitney test was used to analyse categorical variables. These included gender, BMI, ASA classification, type of operation, inpatient complications, drain insertion, postoperative ICU care, and urinary catheterisation. Spearman's rank correlation coefficient was used to analyse continuous variables including age, preoperative haemoglobin level, and blood transfusion. Following univariate analysis, significant predictive factors were subjected to multivariable linear regression analysis to test the effect of each significant factor after adjusting for the others. A P value of $\leq 0.05$ was considered statistically significant.

\section{Results}

A total of 1622 patients were reviewed in this study. Patients who received total hip replacement and revision total knee replacement in our centre were excluded. The mean (range) and median LOS were 
6.8 (3-46) days and 6 days, respectively. The Table multivariate analysis.

shows the categories for each predictive factor, the

Age; ASA class; type of operation; preoperative number of patients in each category, the mean LOS haemoglobin level; in-patient complications; for each category, and the P values for univariate and requirement for blood transfusion, drain insertion,

TABLE. Predictors of length of hospital stay after primary total knee replacement

\begin{tabular}{|c|c|c|c|c|}
\hline Predictor & No. of patients & $\begin{array}{l}\text { Mean length of } \\
\text { stay (days) }\end{array}$ & $\begin{array}{c}P \text { value (univariate } \\
\text { analysis) }\end{array}$ & $\begin{array}{c}\text { P value (multivariate } \\
\text { analysis) }\end{array}$ \\
\hline \multicolumn{5}{|c|}{ Age-group (years) } \\
\hline$<60$ & 255 & 6.16 & & \\
\hline $60-70$ & 676 & 6.34 & & \\
\hline $71-80$ & 575 & 7.27 & & \\
\hline$>80$ & 116 & 8.59 & $<0.001$ & 0.005 \\
\hline \multicolumn{5}{|l|}{ Gender } \\
\hline Male & 500 & 7.06 & & \\
\hline Female & 1122 & 6.68 & 0.602 & - \\
\hline \multicolumn{5}{|c|}{ Body mass index $\left(\mathrm{kg} / \mathrm{m}^{2}\right)$} \\
\hline$\leq 30$ & 1210 & 6.78 & & \\
\hline$>30$ & 412 & 6.86 & 0.568 & - \\
\hline \multicolumn{5}{|l|}{ ASA class* } \\
\hline 1 or 2 & 334 & 5.83 & & \\
\hline 3 & 133 & 6.71 & $<0.001$ & $<0.001$ \\
\hline \multicolumn{5}{|c|}{ Type of operation } \\
\hline Unilateral & 1478 & 6.68 & & \\
\hline Bilateral & 144 & 8.05 & $<0.001$ & 0.002 \\
\hline \multicolumn{5}{|c|}{ Preoperative haemoglobin level (g/L) } \\
\hline$<120$ & 205 & 7.78 & & \\
\hline $120-129$ & 378 & 7.08 & & \\
\hline $130-139$ & 511 & 6.57 & & \\
\hline$\geq 140$ & 528 & 6.45 & $<0.001$ & 0.291 \\
\hline \multicolumn{5}{|c|}{ Blood transfusion (units) } \\
\hline 0 & 1539 & 6.56 & & \\
\hline 1 & 13 & 7.92 & & \\
\hline 2 & 58 & 10.57 & & \\
\hline$\geq 3$ & 12 & 17.83 & $<0.001$ & $<0.001$ \\
\hline \multicolumn{5}{|c|}{ Drain insertion } \\
\hline Yes & 1386 & 677.00 & & \\
\hline No & 236 & 6.98 & 0.012 & 0.163 \\
\hline \multicolumn{5}{|c|}{ Postoperative ICU care } \\
\hline Yes & 46 & 8.52 & & \\
\hline No & 1576 & 6.75 & $<0.001$ & 0.003 \\
\hline \multicolumn{5}{|c|}{ In-patient complications } \\
\hline Yes & 73 & 10.74 & & \\
\hline No & 1549 & 6.62 & $<0.001$ & $<0.001$ \\
\hline \multicolumn{5}{|c|}{ Urinary catheterisation } \\
\hline Yes & 146 & 9.19 & & \\
\hline No & 1476 & 6.56 & $<0.001$ & $<0.001$ \\
\hline
\end{tabular}

Abbreviations: ASA = American Society of Anesthesiologists physical status classification; ICU = Intensive Care Unit

* ASA classification has only been documented in the Clinical Management System since August 2014 
postoperative ICU care, and urinary catheterisation were significant predictive factors in the univariate analysis. When these significant factors were adjusted for the effect of the other factors using multiple linear regression, only advanced age; ASA class 3; bilateral TKR; in-patient complications; and the need for blood transfusion, postoperative ICU care, and urinary catheterisation remained significant.

\section{Discussion}

Several studies of LOS in a Caucasian population have been published, but the study samples were usually highly heterogeneous and included patients with total hip as well as unicompartmental knee replacement. $^{3,4}$ This is the first study to exclusively examine the LOS following TKR in a Chinese population. We believe both cultural-specific patient factors and the unique hospital setting in Hong Kong significantly influence LOS. Identifying the predictive factors in our own population is important to reduce LOS and the associated cost. Factors that have been shown in previous studies to have an influence include age, ${ }^{5}$ gender, ${ }^{5}$ ASA class, ${ }^{6}$ type of surgery, ${ }^{7}$ requirement for blood transfusion, ${ }^{8}$ and in-patient complications. ${ }^{8,9}$ Data for the influence of $\mathrm{BMI}^{7,8,10}$ and preoperative haemoglobin level $^{3,8,11}$ are equivocal. We also studied factors not previously examined including the need for drain insertion, postoperative ICU admission, and Foley catheterisation due to urinary retention.

This study confirmed other previously reported risk factors for longer LOS. Age and ASA class were expected to be predictors of LOS and were significant in many other studies..$^{3-6}$ Classification of ASA physical status is a measurement of the patient's co-morbidity and general fitness. Patients with advanced age and decreased physical fitness will find the required intensive rehabilitation difficult and thus require a longer hospital stay.

The rehabilitation necessary after TKR is demanding and can account for the longer LOS required following bilateral TKR. ${ }^{7}$ Patients who require bilateral TKR have sequential TKRs performed in a single anaesthetic session. In our study, the mean LOS is 1.37 days longer in such patients. Most patients with degenerative arthritis have disease affecting both knees. Patients who undergo unilateral TKR commonly request TKR for the other side due to significant improvement of symptoms on the operated side. The combined LOS for two admissions is obviously longer than that for a single admission for bilateral TKR. Several previous studies have demonstrated a comparable safety profile between bilateral TKR and unilateral TKR in properly selected patients. ${ }^{12-15}$ Patients with bilateral osteoarthritis of the knee should be encouraged to undergo bilateral TKR provided they can tolerate the procedure.

Blood management has always been a contentious issue in TKR. Both preoperative haemoglobin level and requirement for blood transfusion were significant predictive factors for LOS in our univariate analysis. Only requirement for blood transfusion, however, remained significant after multivariate analysis. This signifies that the association between preoperative haemoglobin level and LOS is due to the requirement for a blood transfusion rather than the effect itself. It is well documented that preoperative haemoglobin level is the single most important predictor of need for blood transfusion following TKR. ${ }^{16}$ This is why preoperative haemoglobin level was a significant predictive factor for LOS in some studies although it is not in our study. Raut et $\mathrm{al}^{8}$ reported a significant association between LOS and both preoperative haemoglobin level and blood transfusion requirement although multivariate analysis was not performed. Husted et $\mathrm{al}^{3}$ reported both preoperative haemoglobin level and blood transfusion to be significant predictive factors for LOS, yet more than half of the patients recruited in their study underwent total hip replacement (THR). The intrinsic difference between THR and TKR explains the difference between our and Husted et al's findings.

Postoperative ICU care delayed rehabilitation and inevitably prolonged LOS. This factor remained significant after adjustment for ASA classification. Most of our patients were admitted to the ICU for postoperative monitoring of medical co-morbidities. A commonly encountered reason for ICU monitoring is obstructive sleep apnoea. ${ }^{17}$ Patients at risk of obstructive sleep apnoea should be identified and referred to an ear, nose, and throat surgeon for assessment and early management. ${ }^{18}$ The need for ICU admission and prolonged LOS may be eliminated if medical conditions are optimised before TKR.

Patients who develop in-patient complications were likely to stay longer in hospital; this is consistent with the findings in the literature. ${ }^{8,9}$ Patients who have complications require further work-up and management, this increases utilisation of resources and cost in addition to the increased LOS. ${ }^{9}$ Every effort should be made to avoid complications. We classified complications into seven groups based on our experience. They included deep vein thrombosis, surgical site infection, periprosthetic fracture, urinary tract infection, pressure sore, chest infection, and pulmonary embolism (Fig 2). Any complication that did not fall into one of these categories was documented as 'others'. The top three complications were deep vein thrombosis, surgical site infection, and periprosthetic fracture; these altogether account for $56 \%$ of all complications. Patients who developed deep vein thrombosis required warfarinisation 
and dose titration prior to discharge. Patients who developed a wound infection required intravenous antibiotics, surgical debridement, and close monitoring of the wound. Those with periprosthetic fracture required protected weight-bearing that complicated rehabilitation. We believe strict adherence to anticoagulation guidelines, meticulous wound care, and careful implant insertion are key to avoid complications, prolonged LOS, and more importantly, patient suffering.

In our centre, a bladder scan is performed in patients who do not pass urine for 8 hours following TKR. Those with a urinary volume of $\geq 500 \mathrm{~mL}$ undergo bladder drainage via a urinary catheter. If the patient cannot pass urine on reassessment, a catheter is left in situ. There is, however, no protocol for catheter removal. The catheter will usually remain in place for 1 to 2 days. In our study, the mean duration of urinary catheterisation was 2.35 (range, 1-15) days (Fig 3). If the patient fails to manage without a urinary catheter, a urological referral is made. This is not ideal as the patient must then remain an in-patient while awaiting urological opinion. We believe close liaison with the urologist should be established to enable such patients to be discharged and subsequently assessed in a urology out-patient clinic.

There were some important negative findings in our study. Most Caucasian studies reveal that women remain in hospital longer than men following TKR. ${ }^{3,5}$ This has been reported to be due to the different gender roles in the family: men could go home earlier because they were more likely to be looked after by their partner. ${ }^{19}$ The situation in Hong Kong is different. Children usually live with or close to their parents for cultural and social reasons. Patients having TKR are cared for by their children, not their partner; this eliminates the effect of gender on LOS.

We did not find a statistically significant contribution of drain insertion. We hypothesise that drain insertion decreases haematoma collection and knee effusion and improves the range of movement and function. Since adequate knee function is required for discharge, LOS could be reduced. The results in this study, however, contradicted this hypothesis.

Evaluating predictive factors for LOS after TKR is the starting point to improve our current practice. Based on this study, we need to establish a protocol to wean patients off a urinary catheter. Early prediction of high-risk patients who will require longer hospitalisation provides the opportunity for better preoperative counselling, anticipation of escalated care, and proactive discharge planning.

Our study is limited by its retrospective nature, with results highly dependent on the accuracy of documentation. We have not precisely recorded the

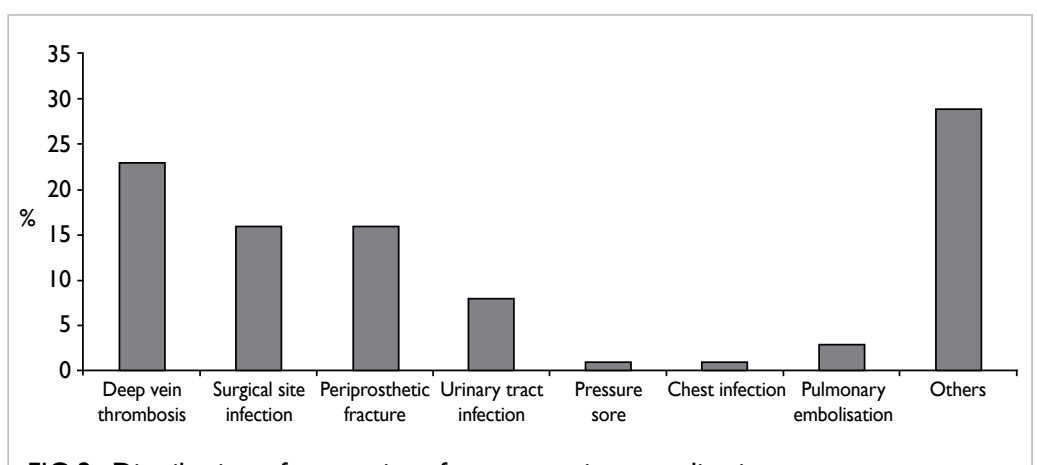

FIG 2. Distribution of categories of postoperative complications

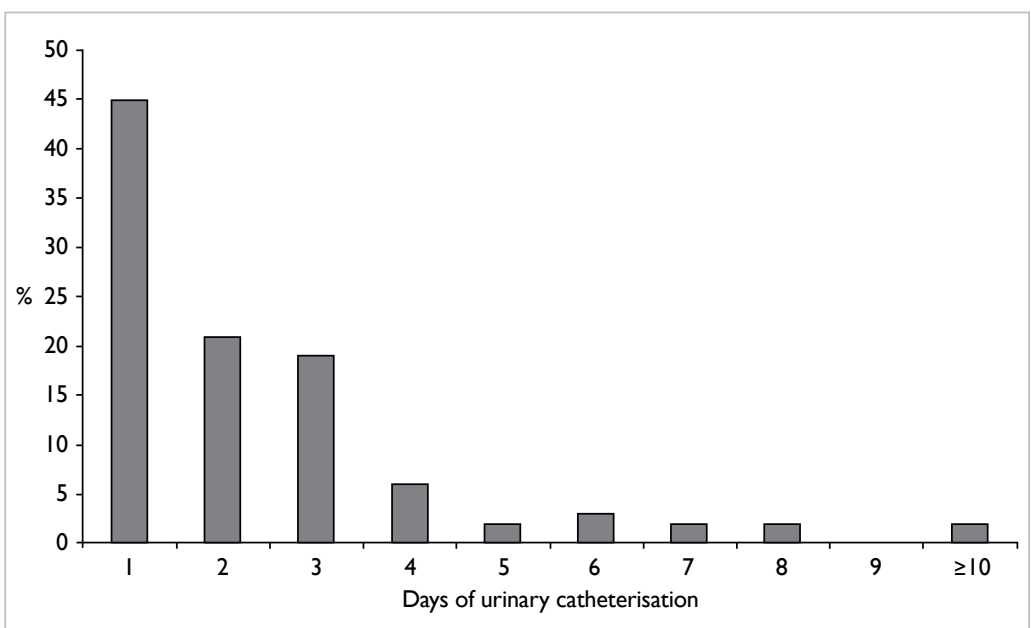

FIG 3. Distribution of number of days of urinary catheterisation

home care status of the patient and the experience of the principal surgeon, as a result these are not used as a covariate in the analysis of our study. The results also reflect the clinical practice of a single centre and may not be generalised to represent the whole population. A territory-wide joint replacement registry could help to analyse predictors of LOS that are specific to Hong Kong.

\section{Conclusion}

Factors that significantly influence LOS following TKR are advanced age; ASA class 3; bilateral operation; in-patient complications; and the need for blood transfusion, postoperative ICU admission, and urinary catheterisation. Identifying these factors will help improve our clinical practice to reduce the LOS and associated cost.

\section{Acknowledgement}

The authors would like to thank Dr Kin-hoi Wong of North District Hospital for his advice regarding statistical analysis. 


\section{Declaration}

All authors have disclosed no conflicts of interest.

\section{References}

1. Yan CH, Chiu KY, Ng FY. Total knee arthroplasty for primary knee osteoarthritis: changing pattern over the past 10 years. Hong Kong Med J 2011;17:20-5.

2. Lee QJ, Mak WP, Wong YC. Mortality following primary total knee replacement in public hospitals in Hong Kong. Hong Kong Med J 2016;22:237-41.

3. Husted H, Holm G, Jacobsen S. Predictors of length of stay and patient satisfaction after hip and knee replacement surgery: fast-track experience in 712 patients. Acta Orthop 2008;79:168-73.

4. Ong PH, Pua YH. A prediction model for length of stay after total and unicompartmental knee replacement. Bone Joint J 2013;95:1490-6.

5. Carter EM, Potts HW. Predicting length of stay from an electronic patient record system: a primary total knee replacement example. BMC Med Inform Decis Mak 2014;14:26.

6. van den Belt L, van Essen P, Heesterbeek PJ, Defoort KC. Predictive factors of length of hospital stay after primary total knee arthroplasty. Knee Surg Sports Traumatol Arthrosc 2015;23:1856-62.

7. Halawi MJ, Vovos TJ, Green CL, Wellman SS, Attarian DE, Bolognesi MP. Preoperative predictors of extended hospital length of stay following total knee arthroplasty. J Arthroplasty 2015;30:361-4.

8. Raut S, Mertes SC, Muniz-Terrera G, Khanduja V. Factors associated with prolonged length of stay following a total knee replacement in patients aged over 75 . Int Orthop 2012;36:1601-8.

9. El Bitar YF, Illingworth KD, Scaife SL, Horberg JV, Saleh KJ. Hospital length of stay following primary total knee arthroplasty: data from the nationwide inpatient sample database. J Arthroplasty 2015;30:1710-5

10. Lozano LM, Tió M, Rios J, et al. Severe and morbid obesity $\left(\mathrm{BMI} \geq 35 \mathrm{~kg} / \mathrm{m}^{2}\right)$ does not increase surgical time and length of hospital stay in total knee arthroplasty surgery. Knee Surg Sports Traumatol Arthrosc 2015;23:1713-9.

11. Jonas SC, Smith HK, Blair PS, Dacombe P, Weale AE. Factors influencing length of stay following primary total knee replacement in a UK specialist orthopaedic centre. Knee 2013;20:310-5.

12. Cohen RG, Forrest CJ, Benjamin JB. Safety and efficacy of bilateral total knee arthroplasty. J Arthroplasty 1997;12:497-502.

13. Jain S, Wasnik S, Mittal A, Sohoni S, Kasture S. Simultaneous bilateral total knee replacement: a prospective study of 150 patients. J Orthop Surg (Hong Kong) 2013;21:19-22.

14. Spicer E, Thomas GR, Rumble EJ. Comparison of the major intraoperative and postoperative complications between unilateral and sequential bilateral total knee arthroplasty in a high-volume community hospital. Can J Surg 2013;56:311-7.

15. Sheth DS, Cafri G, Paxton EW, Namba RS. Bilateral simultaneous vs staged total knee arthroplasty: a comparison of complications and mortality. J Arthroplasty 2016;31:212-6.

16. Guerin S, Collins C, Kapoor H, McClean I, Collins D. Blood transfusion requirement prediction in patients undergoing primary total hip and knee arthroplasty. Transfus Med 2007;17:37-43.

17. Kaw R, Pasupuleti V, Walker E, Ramaswamy A, FoldvarySchafer N. Postoperative complications in patients with obstructive sleep apnea. Chest 2012;141:436-41.

18. Auckley D, Bolden N. Preoperative screening and perioperative care of the patient with sleep-disordered breathing. Curr Opin Pulm Med 2012;18:588-95.

19. Baker DW, Hasnain-Wynia R, Kandula NR, Thompson JA, Brown ER. Attitudes toward health care providers, collecting information about patients' race, ethnicity, and language. Med Care 2007;45:1034-42. 